\title{
Replication and Mutagenesis of UV-Damaged DNA Templates in Human and Monkey Cell Extracts
}

\author{
MICHAEL P. CARTY, ${ }^{1 *}$ JANET HAUSER,${ }^{2}$ ARTHUR S. LEVINE, ${ }^{2}$ AND KATHLEEN DIXON ${ }^{1}$ \\ Department of Environmental Health, University of Cincinnati, Cincinnati, Ohio 45267-0056, ${ }^{1}$ and Section on \\ Viruses and Cellular Biology, National Institute of Child Health and Human Development, \\ Bethesda, Maryland $20892^{2}$
}

Received 8 June 1992/Accepted 28 October 1992

\begin{abstract}
We have used in vitro DNA replication systems from human HeLa cells and monkey CV-1 cells to replicate a UV-damaged simian virus 40-based shuttle vector plasmid, pZ189. We found that replication of the plasmid was inhibited in a UV fluence-dependent manner, but even at UV fluences which caused damage to essentially all of the plasmid molecules some molecules became completely replicated. This replication was accompanied by an increase (up to 15-fold) in the frequency of mutations detected in the supF gene of the plasmid. These mutations were predominantly $\mathrm{G}: \mathrm{C} \rightarrow \mathrm{A}: \mathrm{T}$ transitions similar to those observed in vivo. Treatment of the UV-irradiated plasmid DNA with Escherichia coli photolyase to reverse pyrimidine cyclobutane dimers (the predominant UV-induced photoproduct) before replication prevented the UV-induced inhibition of replication and reduced the frequency of mutations in $\sup F$ to background levels. Therefore, the presence of pyrimidine cyclobutane dimers in the plasmid template appears to be responsible for both inhibition of replication and mutation induction. Further analysis of the replication of the UV-damaged plasmid revealed that closed circular replication products were sensitive to $T 4$ endonuclease $V$ (a pyrimidine cyclobutane dimer-specific endonuclease) and that this sensitivity was abolished by treatment of the replicated DNA with $E$. coli photolyase after replication but before $\mathbf{T} 4$ endonuclease treatment. These results demonstrate that these closed circular replication products contain pyrimidine cyclobutane dimers. Density labeling experiments revealed that the majority of plasmid DNA synthesized in vitro in the presence of bromodeoxyuridine triphosphate was hybrid density whether or not the plasmid was treated with UV radiation before replication; therefore, replication of UV-damaged templates appears to occur by the normal semiconservative mechanism. All of these data suggest that replication of UV-damaged templates occurs in vitro as it does in vivo and that this replication results in mutation fixation.
\end{abstract}

Mutations in specific cellular genes (proto-oncogenes) involved in growth regulation play a central role in cancer induction by environmental agents such as UV radiation. These mutations appear to be a consequence of damage introduced into the cellular DNA by exposure to the agent. Excessive exposure to the UV rays of sunlight appears to be responsible for induction of the majority of skin cancers. Presently, approximately 500,000 new cases of skin cancer are diagnosed in the United States each year (24). It is feared that continued depletion of ozone in the atmosphere by chlorofluorocarbons and other pollutants will significantly increase human exposure to the sun's harmful UV radiation, resulting in dramatic increases in skin cancer incidence.

The mechanism by which UV-induced DNA damage causes mutations in humans is not well understood. UV light has been shown to be mutagenic in a variety of repairproficient and repair-deficient mammalian cells in culture (2, $3,7,9)$. The frequency of mutations appears to correlate with the amount of unrepaired DNA damage remaining in the DNA at the time of replication, suggesting that replication of damaged DNA leads to mutation fixation. When mammalian cells in culture are irradiated with UV light, cellular DNA replication is inhibited $(10,12)$. In addition, it has been shown that replication of simian virus 40 (SV40) (1, $14,25)$ and of shuttle vector plasmids $(3,7,9)$ in mammalian cells is inhibited by prior UV irradiation of the viral or plasmid DNA. However, these studies indicate that the

\footnotetext{
* Corresponding author.
}

cellular replication apparatus can accommodate a limited number of UV-induced photoproducts in the DNA template (25). Studies with the SV40-based shuttle vector pZ189 have demonstrated that replication of UV-damaged templates in monkey and human cells is accompanied by an increase in the frequency of mutations $(3,9)$. However, the mechanisms by which DNA damage is accommodated and mutations are fixed during DNA replication are not well understood at the biochemical level.

In order to elucidate the mechanisms of replication of UV-damaged templates and mutation fixation, we felt that it would be desirable to develop an in vitro system in which these processes could be studied at the molecular level. Previous in vitro studies in which purified mammalian DNA polymerases had been used to replicate UV-damaged templates revealed that one of the main replicative polymerases in mammalian cells, polymerase $\alpha$, is blocked by UVinduced lesions in the template DNA $(16,18)$, suggesting that additional factors might be required to allow accommodation of UV-induced lesions in the template. Therefore, to address the question of how UV-damaged DNA is replicated, we have used cell extracts prepared from human (HeLa) and monkey (CV-1) cells by the method of Li and Kelly (13). These unpurified cellular extracts have been shown to carry out normal semiconservative DNA replication of SV40based plasmids when supplemented with SV40 large T antigen (13). As a template, we have used the SV40-based shuttle vector plasmid pZ189 (23). The supF gene of the shuttle vector serves as a mutagenesis target for quantifying and characterizing the mutagenesis that occurs during in 


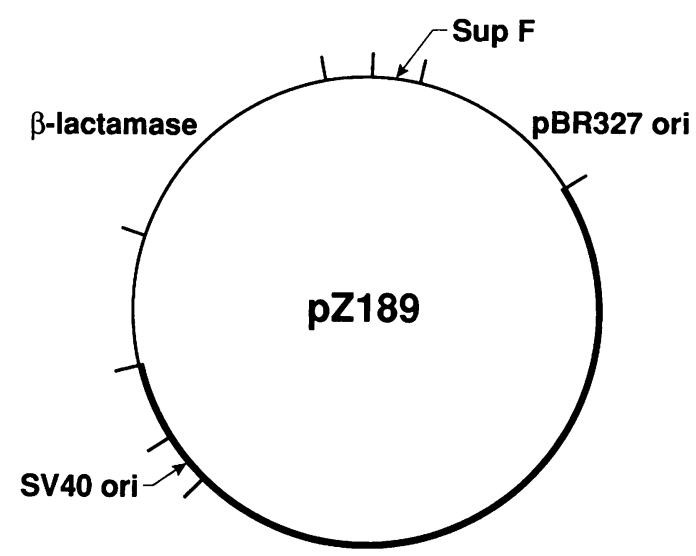

FIG. 1. Structure of the shuttle vector plasmid pZ189. The plasmid contains the origin of replication (pBR327 ori) and the $\beta$-lactamase gene from $\mathrm{pBR} 327$, the sup $F$ mutagenesis marker gene, and the origin of replication (SV40 ori) and early region of SV40 (heavy line) (23).

vitro replication of the vector. This approach has been used previously to analyze the frequency and specificity of spontaneous mutations occurring during DNA replication in extracts of monkey (8) and human (4) cells.

Using this system, we have been able to demonstrate mutation fixation in a cell-free mammalian DNA replication system. In the complete in vitro DNA replication system, replication of UV-damaged DNA results in the generation of mutations which are similar to those induced by UV radiation in whole cells. So far, our experimental results suggest that the process of mutation fixation observed in vitro very closely mimics the process that occurs in vivo. To our knowledge, this is the first demonstration of mutation fixation in a mammalian cell-free system. The establishment of this system offers new experimental approaches for gaining a detailed understanding of the process of mutation fixation at the molecular and biochemical levels.

\section{MATERIALS AND METHODS}

DNA template. The shuttle vector plasmid pZ189 (23) was used as a template for DNA replication in vitro. It contains the SV40 origin of replication, which is required for large$T$-antigen-dependent replication in vitro; the pBR327 origin of replication and the $\beta$-lactamase gene, which allow ampicillin selection in Escherichia coli; and the tyrosine suppressor tRNA gene (supF) as a mutagenesis target (Fig. 1). Plasmid DNA was grown in $E$. coli $\mathrm{HB} 101$ and purified by cesium chloride-ethidium bromide equilibrium sedimentation by Lofstrand Laboratories, Gaithersburg, Md.

UV irradiation of plasmid DNA. Where indicated, the plasmid was irradiated, at a concentration of $100 \mathrm{ng} / \mu \mathrm{l}$, in 10 mM Tris- $\mathrm{HCl}$ (pH 7.6)-1 mM EDTA, in a total volume of 100 $\mu \mathrm{l}$, on ice with a low-pressure mercury lamp $(254 \mathrm{~nm})$.

$T 4$ endonuclease $\mathbf{V}$ treatment of irradiated DNA. The yield of pyrimidine cyclobutane dimers in plasmid DNA was calculated, by using a Poisson distribution, from the proportion of the molecules which became sensitive to nicking by T4 endonuclease V, which specifically nicks DNA at the sites of pyrimidine cyclobutane dimers (22). The pZ189 DNA was irradiated with doses of $0,10,15,20,30$, and $40 \mathrm{~J}$ of UV per $\mathrm{m}^{2}$, as described above. $\mathrm{T} 4$ den $V$ endonuclease $\mathrm{V}$ was purchased from Applied Genetics, Inc., Freeport, N.Y.

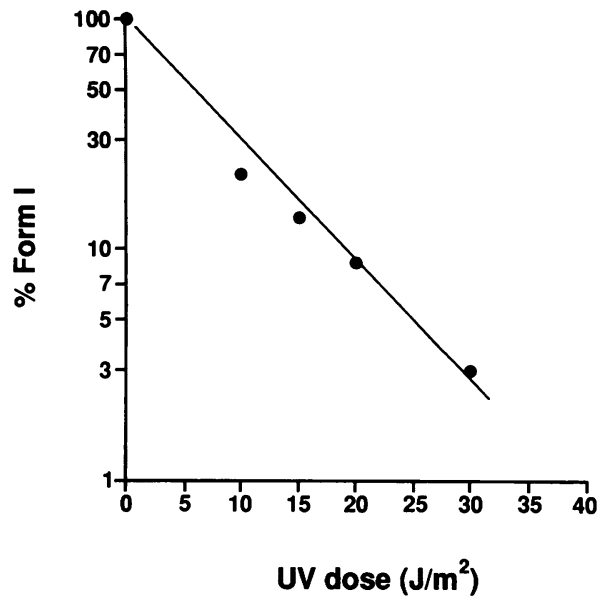

FIG. 2. Sensitivity of UV-irradiated pZ189 to nicking by T4 endonuclease $V$. Vector pZ189 DNA was irradiated with 0 to $30 \mathrm{~J}$ of UV light per $\mathrm{m}^{2}$ and treated with T4 endonuclease as described in Materials and Methods. The reaction products were analyzed by agarose gel electrophoresis. The extent of conversion of form I DNA to relaxed forms was determined by densitometry on a negative of a photograph of the ethidium bromide-stained gel.

Reaction mixtures contained $100 \mathrm{ng}$ of unirradiated or UVirradiated pZ189 DNA, $50 \mathrm{mM} \mathrm{KHPO}{ }_{4}$ (pH 6.5), $100 \mathrm{mM}$ $\mathrm{NaCl}, 1 \mathrm{mM}$ EDTA, $1 \mathrm{mM}$ dithiothreitol (DTT), $1 \mu \mathrm{g}$ of bovine serum albumin, and $1 \mathrm{U}$ of $\mathrm{T} 4$ endonuclease $\mathrm{V}$. Reaction mixtures were incubated at $37^{\circ} \mathrm{C}$ for $1 \mathrm{~h}$, and the DNA was purified by phenol extraction and concentrated by ethanol precipitation. The products were analyzed by agarose gel electrophoresis and visualized by staining the gel in $0.5 \mu \mathrm{g}$ of ethidium bromide per ml. The extent of conversion of completely closed circular (form I) plasmid DNA to nicked circular (form II) DNA was quantitated by densitometry on a photographic negative of the ethidium bromidestained gel. Unirradiated pZ189 DNA is insensitive to nicking by $\mathrm{T} 4$ endonuclease $\mathrm{V}$. Treatment of UV-irradiated (40 $\mathrm{J} / \mathrm{m}^{2}$ ) DNA with photolyase abolished the sensitivity of the DNA to T4 endonuclease V (data not shown), indicating that the T4 endonuclease preparation used here is specific for UV-induced pyrimidine cyclobutane dimers. The amount of T4 endonuclease V-resistant form I decreases exponentially with increasing UV dose, from 0 to $30 \mathrm{~J} / \mathrm{m}^{2}$. The $D_{\mathrm{o}}$ (the dose that results in $37 \% \mathrm{~T} 4$ endonuclease $\mathrm{V}$-resistant form I) is estimated by this method (using Poisson statistics) to be approximately $8 \mathrm{~J} / \mathrm{m}^{2}$ (Fig. 2), a value similar to that reported previously for UV irradiation of pZ189 DNA (17). At this dose there is an average of one T4 endonuclease V-sensitive site per plasmid molecule. Assuming a linear increase in pyrimidine cyclobutane dimers with dose and a random distribution of damage, we used Poisson statistics to estimate that irradiation at $40 \mathrm{~J} / \mathrm{m}^{2}$ results in an average of approximately five pyrimidine dimers per plasmid; $99 \%$ of the plasmid molecules would be expected to have at least one pyrimidine cyclobutane dimer in one or the other DNA strand. At this dose each strand would be expected to have an average of 2.5 dimers; therefore, the probability of one or more dimers on a single strand is about 0.918 , and about $84 \%$ of the molecules would be expected to have at least one pyrimidine cyclobutane dimer on each strand.

Cell extracts. Replication-competent cytosolic extracts were prepared from monolayer cultures of human $\mathrm{HeLa}$ cells and African green monkey kidney CV-1 cells (TC7 
clone) by hypotonic extraction in $20 \mathrm{mM}$ HEPES $(\mathrm{N}-2-$ hydroxyethylpiperazine- $N^{\prime}$-2-ethanesulfonic acid) ( $\left.\mathrm{pH} 7.5\right)-$ $5 \mathrm{mM} \mathrm{MgCl} 2-1.5 \mathrm{mM} \mathrm{KCl}-1 \mathrm{mM}$ DTT (13) followed by clarification by centrifugation at $10,000 \mathrm{rpm}$ in an Eppendorf model 5402 centrifuge for $10 \mathrm{~min}$. SV40 large $T$ antigen, purified from infected cells by immunoaffinity chromatography, was purchased from Molecular Biology Resources, Madison, Wis., and purified from infected cells by immunoaffinity chromatography.

DNA synthesis in vitro. DNA synthesis reaction mixtures with HeLa cell extract contained (in a final volume of $30 \mu \mathrm{l}$ ) $30 \mathrm{mM}$ HEPES (pH 7.5); $7 \mathrm{mM} \mathrm{MgCl}_{2} ; 0.5 \mathrm{mM}$ DTT; 100 $\mu \mathrm{M}$ each dATP, dGTP, and dTTP; $50 \mu \mathrm{M}$ dCTP; $10 \mu \mathrm{Ci}$ of $\left[\alpha^{-32} \mathrm{P}\right] \mathrm{dCTP} ; 200 \mu \mathrm{M}$ each GTP, UTP, and CTP; $40 \mathrm{mM}$ ATP; $40 \mathrm{mM}$ creatine phosphate; $10 \mu \mathrm{g}$ of creatine kinase; 25 ng of pZ189 DNA; $3 \mu \mathrm{g}$ of SV40 large T antigen; and approximately $60 \mu \mathrm{g}$ of HeLa cell extract protein. In density labeling experiments with $\mathrm{BrdU}$, reactions were carried out with $100 \mu \mathrm{M}$ BrdU triphosphate (BrdUTP) (Sigma) in place of dTTP. For CV-1 extracts, reaction conditions were the same except that the total reaction volume was $60 \mu \mathrm{l}$ and dCTP was reduced to $25 \mu \mathrm{M}$. All reaction mixtures were incubated at $37^{\circ} \mathrm{C}$ and then reactions were stopped by the addition of $100 \mu \mathrm{g}$ of proteinase $\mathrm{K}$ per $\mathrm{ml}$ and $15 \mathrm{mM}$ EDTA; mixtures were then incubated at $37^{\circ} \mathrm{C}$ for $30 \mathrm{~min}$. DNA was purified by incubation with $5.6 \mathrm{M} \mathrm{CsCl}$ at room temperature overnight and filtered through a $0.45-\mu \mathrm{m}$-pore-size Millex-HA filter (Millipore Corp., Bedford, Mass.); filtration was followed by spin dialysis against Tris-EDTA ( $\mathrm{pH} 7.6$ ) in Centricon 30 microconcentrators (Amicon), as described previously (8). These purification conditions select against high-molecular-weight concatenates and perhaps some replicative intermediates.

Density gradient ultracentrifugation. DNA synthesized in vitro, with BrdUTP in place of dTTP as described above, was purified by the cesium chloride method described in the previous paragraph. The DNA was then centrifuged in $5 \mathrm{ml}$ of cesium chloride (refractive index, 1.41), under neutral conditions (10 mM Tris [pH 7.6], $1 \mathrm{mM}$ EDTA), for $70 \mathrm{~h}$ at $30,000 \mathrm{rpm}$ in a Beckman model L8-70 ultratrifuge at $18^{\circ} \mathrm{C}$. Fractions were collected from the bottom of the tube, and the radioactivity in each fraction was counted. The refractive indices of a number of fractions along the gradient were determined with a Bausch \& Lomb refractometer.

Photolyase treatment. Plasmid DNA was incubated with 5 $\mu \mathrm{g}$ of $E$. coli photolyase (a generous gift of Aziz Sancar, University of North Carolina) in $50 \mathrm{mM}$ Tris- $\mathrm{HCl}$ (pH 7.6)-10 mM NaCl-1 mM EDTA-10 mM DTT in the dark on ice for $30 \mathrm{~min}$ and then exposed to $365 \mathrm{~nm}$ of light for $1 \mathrm{~h}$ at room temperature. The DNA was purified by phenol extraction and ethanol precipitation. The DNA was quantitated spectrophotometrically before use in DNA replication.

Mutagenesis assay. $E$. coli MBM7070, which has a suppressible amber mutation in the $\beta$-galactosidase gene, was transformed with the products of DNA replication by electroporation by using a Cell-Porator electroporation procedure (Bethesda Research Laboratories, Gaithersburg, Md.). The DNA was treated first with DpnI to remove unreplicated input DNA and then with $E$. coli dam methylase to restore the bacterial methylation pattern necessary to allow efficient expression of base substitutions as mutations in this system (8). Mutants are scored as white or light blue colonies after being plated on agar plates containing 5-bromo-4-chloro-3indoyl- $\beta$-D-galactoside, isopropyl- $\beta$-D-thiogalactopyranoside, and ampicillin (9). Transformants which carry the wild-type sup $F$ gene form blue colonies on these plates.
DNA sequencing. Plasmid DNA was sequenced by the dideoxy chain termination method, by using reverse transcriptase, as described previously $(4,8)$.

\section{RESULTS}

UV irradiation of the DNA template inhibits incorporation of $\left[{ }^{32} \mathbf{P}\right] \mathbf{d C T P}$ during replication in vitro. In order to determine whether UV-induced photoproducts in the DNA template interfere with DNA replication in vitro as they do in vivo, we have measured the capacity of UV-damaged pZ189 to serve as a template for in vitro DNA replication. UVirradiated or unirradiated pZ189 DNA was incubated with HeLa or CV-1 cell extracts and SV40 large T antigen under replication conditions in the presence of $\left[{ }^{32} \mathrm{P}\right] \mathrm{dCTP}$ (as described in Materials and Methods). At various times during incubation, samples were withdrawn and the radioactive label incorporated into acid-precipitable material was measured. The results in Fig. 3 indicate that there is UV fluence-dependent inhibition of $\left[{ }^{32} \mathrm{P}\right] \mathrm{dCTP}$ incorporation into acid-precipitable material in extracts from both cell types. However, even at the highest UV fluence examined at which the plasmids would be expected to contain an average of 12 pyrimidine cyclobutane dimers, incorporation is not completely inhibited. In the absence of $\mathrm{T}$ antigen, little incorporation of label was observed on either undamaged or UV-irradiated templates (Fig. 3). Therefore, the label incorporation observed is $T$ antigen dependent and presumably represents primarily replicative DNA synthesis rather than repair-type synthesis.

To determine whether replication of the UV-damaged vector in the extracts resulted in the production of closed circular products, the plasmid DNA was purified from the reaction mixture and analyzed by agarose gel electrophoresis. Agarose gel electrophoresis, in the presence of $5 \mu \mathrm{g}$ of ethidium bromide per $\mathrm{ml}$, revealed form I DNA (supercoiled and relaxed closed circles), form II DNA (nicked circles), and molecules having slower mobility which presumably represent replicative intermediates or plasmid dimers (Fig. 4). Overall, production of labeled form I DNA was inhibited in a UV fluence-dependent manner. After $3 \mathrm{~h}$ of incubation in HeLa cell extracts, the extent of inhibition is about $35 \%$ at $10 \mathrm{~J} / \mathrm{m}^{2}$ and increases to approximately $80 \%$ at $40 \mathrm{~J} / \mathrm{m}^{2}$, as determined by direct scintillation counting of the radioactivity in the form I band excised from the gel. These results are similar to those in previous reports on the effects of UV irradiation on DNA replication in vitro $(5,6)$. In CV-1 cell extracts, the inhibition of the production of form I molecules appears to be somewhat more dramatic than in HeLa cell extracts (5).

In the absence of large $\mathrm{T}$ antigen, there is no detectable incorporation of radioactivity into undamaged plasmid DNA observed by agarose gel electrophoresis and autoradiography (Fig. 4), indicating that the low background of incorporation observed by trichloroacetic acid precipitation (Fig. 3) is not detectable in plasmid DNA by this method.

Analysis of DNA replication by equilibrium centrifugation in cesium chloride. The next experiment was carried out to determine whether replication of UV-damaged templates in vitro occurs by a semiconservative mechanism as does the replication of undamaged templates (13). Replication of UV-irradiated plasmid (average of five pyrimidine cyclobutane dimers per plasmid) was carried out in the presence of BrdUTP in place of dTTP to provide a density label, and the products were analyzed by equilibrium sedimentation in $\mathrm{CsCl}$. When either UV-irradiated or unirradiated templates 

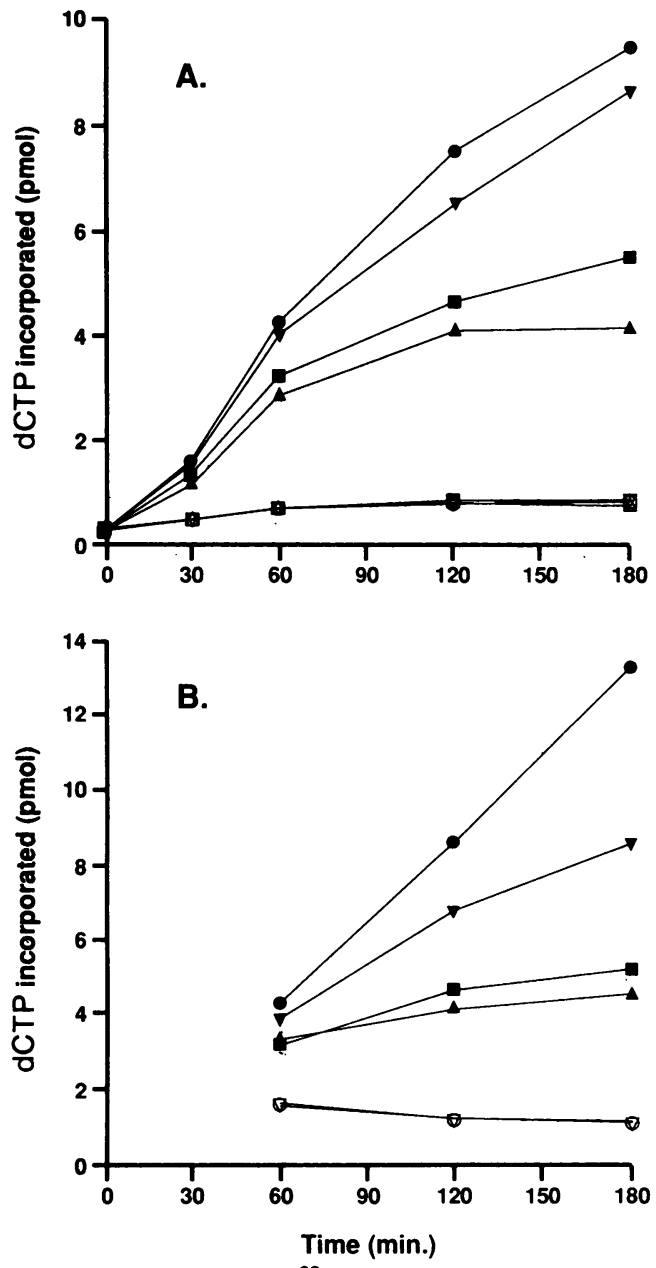

FIG. 3. Incorporation of $\left[{ }^{32} \mathrm{P}\right] \mathrm{dCTP}$ into UV-irradiated pZ189 DNA during DNA replication in vitro. (A) In vitro DNA replication reactions were carried out as described in Materials and Methods with extracts prepared from $\mathrm{HeLa}$ cells and unirradiated or UVirradiated pZ189 DNA. Unirradiated DNA was also incubated with HeLa extract in the absence of SV40 large T antigen. At the times indicated, aliquots were withdrawn and spotted onto Whatman $3 \mathrm{MM}$ filter paper discs, and the extent of incorporation was determined by precipitation of the DNA in cold $10 \%$ trichloroacetic acid containing $10 \mathrm{mM}$ sodium $\mathrm{PP}_{\mathrm{i}}$. The filters were then washed and counted by liquid scintillation counting. Symbols: $O$ and $O$, unirradiated; $\nabla$ and $\nabla, 10 \mathrm{~J} / \mathrm{m}^{2} ; \boldsymbol{\square}$ and $\square, 40 \mathrm{~J} / \mathrm{m}^{2} ; \Delta$ and $\Delta, 100 \mathrm{~J} / \mathrm{m}^{2}$. Closed symbols show results with $\mathrm{T}$ antigen, and open symbols show results without $T$ antigen. (B) Procedures were same as for panel A, except that extracts of CV-1 monkey cell were used for the in vitro replication reaction. Symbols: $\odot$ and $O$, unirradiated; $\nabla$ and $\nabla, 20 \mathrm{~J} / \mathrm{m}^{2} ; \square, 50 \mathrm{~J} / \mathrm{m}^{2} ; \Delta, 100 \mathrm{~J} / \mathrm{m}^{2}$. Closed and open symbols are the same as for panel $\mathrm{A}$.

were used, the majority of replicated molecules banded at the position of intermediate (HL) density in the gradient (Fig. 5A and B). This is expected if most of the replicated molecules have undergone a single round of replication. An additional peak of radioactivity (amounting to about $12 \%$ of the total) banding at the position of fully substituted DNA $(\mathrm{HH})$ is observed when undamaged DNA is used as the template, indicating further rounds of replication. The banding pattern of undamaged DNA replicated in vitro in the presence of BrdUTP (Fig. 5A) is essentially identical to that reported previously (26). In the case of UV-irradiated DNA, some heavy-heavy DNA may also be present, suggesting that a small amount of second-round replication may also occur on this template (Fig. 5B). The banding pattern of unsubstituted, undamaged pZ189 replicated in the absence of BrdUTP is provided for comparison (Fig. 5C). Little or no labeled material was observed between the positions of $\mathrm{HL}$ and LL DNA, indicating the absence of detectable levels of partially replicated, repaired, or recombined molecules (see Discussion). The extent of inhibition of DNA synthesis observed in this experiment was approximately $85 \%$, similar to that observed in experiments carried out in the absence of BrdUTP, indicating that the presence of BrdUTP does not alter the inhibition of DNA replication by UV damage. We conclude from these experiments that the majority of the replication on UV-damaged templates appears to be semiconservative and cannot be explained solely by multiple rounds of replication of the extremely small fraction $(<1 \%)$ of undamaged templates.

Mutagenesis following replication of UV-irradiated DNA in HeLa cell extracts in vitro. To determine whether mutation fixation occurs as a result of replication of UV-irradiated plasmid in vitro, we analyzed the frequency of mutations occurring in the mutagenesis marker (supF) gene of the pZ189 plasmid. After replication of UV-irradiated plasmid in vitro, DNA was purified and then treated with the enzyme DpnI to cleave unreplicated input DNA. The input DNA carries the bacterial host methylation pattern and is sensitive to DpnI cleavage; after a single round of in vitro replication, the DNA becomes hemimethylated and is resistant to cleavage (8). As shown in Fig. 6, almost all of the labeled DNA is resistant to this enzyme after in vitro replication. Following treatment with dam methylase, to restore the bacterial methylation necessary for efficient expression of mutations in bacteria (8), E. coli MBM7070 was transformed with the product DNA. Mutants were scored as white or light blue colonies in a background of dark blue colonies. Table 1 shows the mutant frequencies measured following replication of undamaged or UV-irradiated $\left(40 \mathrm{~J} / \mathrm{m}^{2}\right)$ pZ189 DNA. In experiments 1 and 2, there were 14- and 8-fold increases, respectively, in the mutant frequency when UV-irradiated DNA rather than unirradiated DNA was used as the template. The mutant frequencies following replication of undamaged pZ189 in these experiments are comparable to values reported previously for replication of undamaged DNA templates in vitro $(4,8,19)$.

To analyze whether UV-induced mutations are present in closed circular replication products, we isolated closed circular (form I) DNA by electroelution from an agarose gel and then treated this DNA with DpnI and dam methylase and used it to transform $E$. coli MBM7070. The mutant frequency in form I DNA (Table 1) is similar to that in the total DNA. These data indicate that mutations are present in closed circular DNA rather than arising from, for example, processing of gapped replicative intermediates by the bacterial host.

The mutant frequency was also measured following direct transformation of unirradiated or UV-irradiated DNA into $E$. coli MBM7070, without replication in the extract. This gives a mutant frequency of about $0.003 \%$ (Table 1 ). Thus, UVinduced DNA damage in unreplicated plasmid DNA does not measurably increase the background mutant frequency observed with $E$. coli MBM7070 under our transformation conditions. This result is consistent with previous observations made in this and other laboratories $(2,3,7,8,17)$. Incubation of unirradiated or UV-irradiated DNA in the extract in the absence of large $T$ antigen and hence in the 


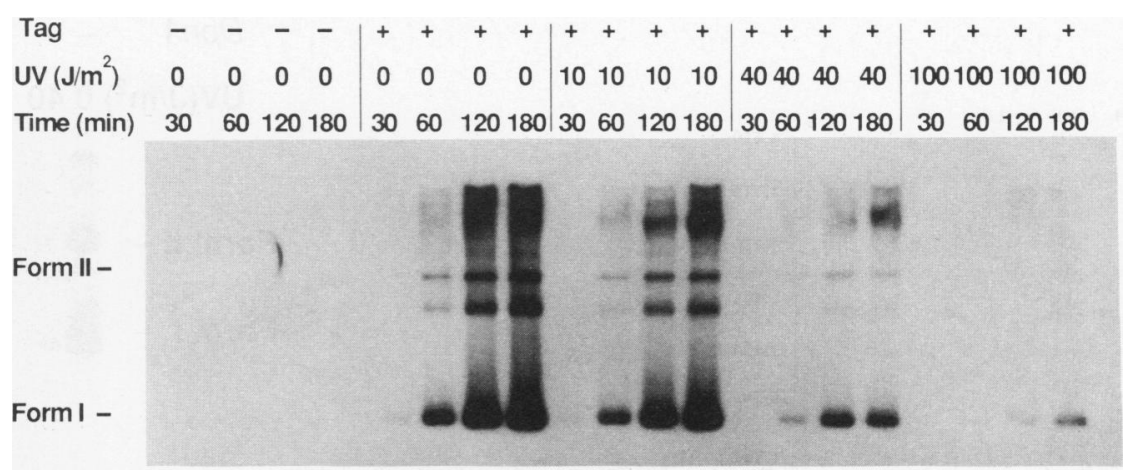

FIG. 4. Inhibition of DNA replication in vitro by UV irradiation of pZ189. Unirradiated or UV-irradiated $\left(10,40\right.$, or $\left.100 \mathrm{~J} / \mathrm{m}^{2}\right) \mathrm{pZ189} \mathrm{was}$ incubated with HeLa cell extract under replication conditions (Materials and Methods) or in the absence of large $\mathrm{T}$ antigen (Tag). At the indicated times, aliquots were withdrawn from the reaction mixture. The reaction was stopped and DNA was purified by the CsCl method as described in Materials and Methods. The products were analyzed by agarose gel electrophoresis in the presence of $5 \mu \mathrm{g}$ of ethidium bromide per $\mathrm{ml}$. The gel was then dried and exposed for autoradiography. The positions of radioactively labeled form I (completely closed circular) and form II (nicked circular) plasmid DNAs were identified by comparison with the positions of these forms in unlabeled marker pZ189 plasmid run in parallel on the same gel.

absence of replication does not result in a significantly increased mutant frequency (Table 1). In this case, DpnI treatment was omitted to prevent cleavage of unreplicated plasmid DNA. These results indicate that plasmid DNA replication is required for mutagenesis to be observed in vitro.

Specificity of mutations observed in vitro. Plasmid DNA molecules from a number of white and light blue colonies, appearing after transformation of $E$. coli MBM7070 with the products of in vitro replication of UV-irradiated pZ189, were isolated and sequenced. Of 21 mutants sequenced, all were base substitutions, with 16 being single base substitutions and 5 being double base substitutions (Table 2). All were at sites of adjacent pyrimidines in the $\sup F$ gene, potential sites of UV-induced premutagenic lesions. Of the 26 total base substitutions, $85 \%$ were $\mathrm{G}: \mathrm{C} \rightarrow \mathrm{A}: \mathrm{T}$ transitions. This predominance of transitions at $\mathrm{G}: \mathrm{C}$ base pairs is characteristic of UV-induced mutations in vivo $(3,9)$. Base substitution mutations (mainly $\mathrm{G}: \mathrm{C} \rightarrow \mathrm{A}: \mathrm{T}$ transitions) also arose during in vitro replication of UV-damaged plasmids in CV-1 cell extracts (data not shown). Further characterization of mutations generated during replication of UV-irradiated plasmid in vitro will be the subject of a separate report.

Treatment of $U V$-irradiated DNA with $E$. coli photolyase before replication prevents inhibition of DNA replication and decreases mutagenesis. In vivo, pyrimidine cyclobutane dimers (the major photoproduct induced by $254 \mathrm{~nm}$ of UV) are responsible for much of the inhibition of DNA replication and mutagenesis observed in the pZ189 shuttle vector system (17). To test whether this lesion is responsible for the observed inhibition of replication of UV-irradiated plasmid in vitro, pZ189 was irradiated with $40 \mathrm{~J}$ of UV light per $\mathrm{m}^{2}$ and then treated with $E$. coli photolyase plus 365 -nm light, which specifically reverses pyrimidine cyclobutane dimers but not other UV photoproducts in DNA (20). DNA treated with photolyase was then purified free of the enzyme, and the reversal of pyrimidine cyclobutane dimers was confirmed by the loss of sensitivity of the DNA to nicking by T4 endonuclease V (data not shown). The UV-irradiated, photolyase-treated plasmid DNA was then used as a template for in vitro replication. Treatment of UV-irradiated DNA with photolyase before replication substantially reduced the UV-induced inhibition of replication (Fig. 7).
If pyrimidine cyclobutane dimers are responsible for UVinduced mutations in vitro as they are in vivo, the photolyase treatment of UV-irradiated plasmid before in vitro replication should also lead to a reduction in the mutations observed following replication. That this is observed is shown in Table 3; the increase in mutant frequency observed with UV-irradiated templates is essentially eliminated by treatment of the DNA with photolyase. The ability of photolyase to reverse the inhibition of replication induced by UV irradiation and to eliminate the UV-induced increase in mutant frequency indicates that cyclobutane pyrimidine dimers are responsible for both the inhibition of replication and the increase in mutant frequency.

Replicated, UV-damaged DNA contains T4 endonuclease V-sensitive sites. If the mutations we observe following replication of UV-damaged templates in vitro arise as a consequence of accommodation of UV damage during replication, we would expect that replicated molecules would retain UV photoproducts in their parental strands. To determine whether plasmid DNA which had become completely replicated in vitro to yield closed circular (form I) DNA still contains pyrimidine cyclobutane dimers, replicated DNA (Fig. 4) was treated with T4 endonuclease V (as described in Materials and Methods). This enzyme specifically nicks DNA at sites of pyrimidine cyclobutane dimers by combined glycosylase and endonuclease activities (22). Following treatment, DNA was analyzed by agarose gel electrophoresis (Fig. 8). T4 endonuclease $\mathrm{V}$ treatment resulted in nicking of UV-damaged replicated form I DNA, while unirradiated replicated DNA was insensitive to nicking by T4 endonuclease $\mathrm{V}$ (Fig. 8A). These results indicate that while replication is inhibited by about $80 \%$ by $40 \mathrm{~J}$ of $\mathrm{UV}$ per $\mathrm{m}^{2}$, complete synthesis of form I DNA containing pyrimidine dimers can be carried out by the HeLa cell replication complex in vitro. Evaluation of the extent of conversion of form I to form II by densitometry of these autoradiograms revealed that approximately 80 to $90 \%$ of the labeled form I molecules were converted to form II under these conditions. Replication of UV-damaged pZ189 in CV-1 cell extracts also led to the production of T4 endonuclease $\mathrm{V}$-sensitive form I molecules (Fig. 8B). In this case, when DNA irradiated with $30 \mathrm{~J}$ of UV per $\mathrm{m}^{2}$ was replicated in vitro, about 40 to $50 \%$ of the form I molecules were sensitive to nicking by the enzyme (deter- 

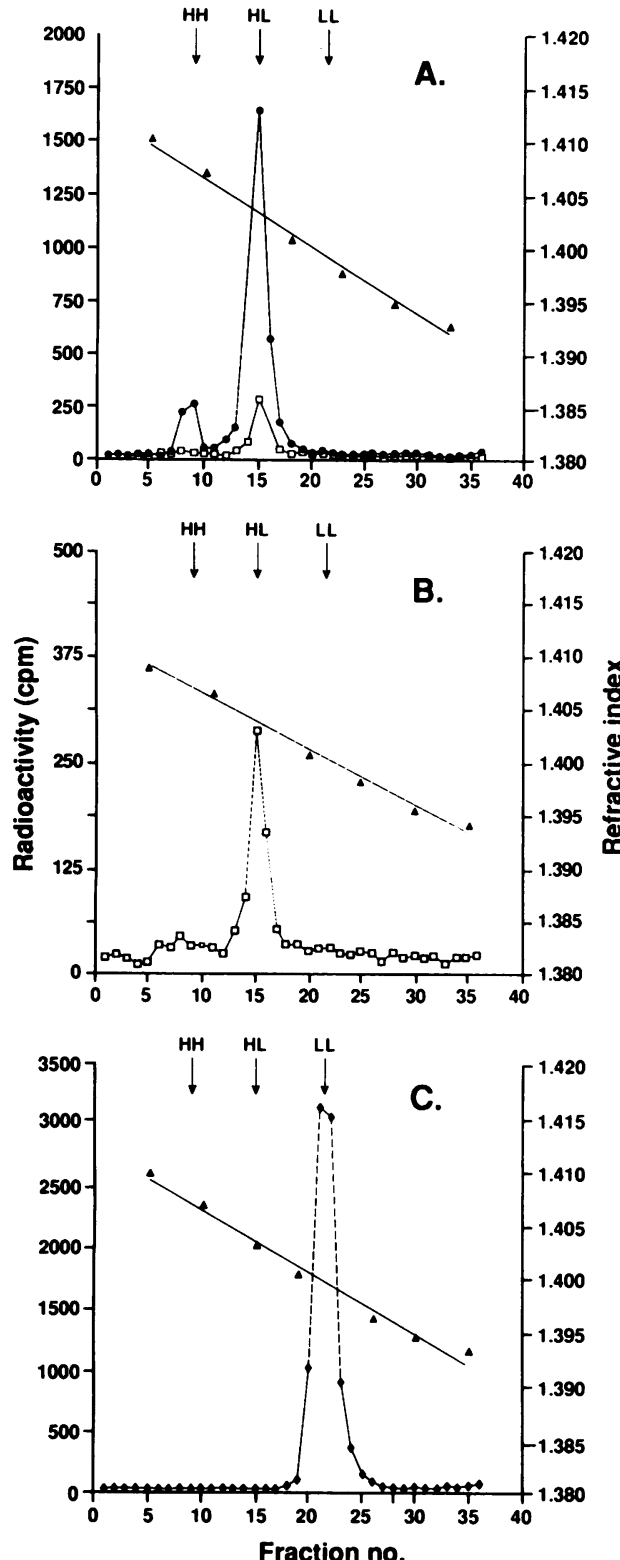

FIG. 5. Isopycnic centrifugation of DNA synthesized in vitro in HeLa cell extracts. Vector DNA was replicated for $180 \mathrm{~min}$ in vitro in the presence of $10 \mu \mathrm{Ci}$ of $\left[\alpha^{-32} \mathrm{P}\right] \mathrm{dCTP}$ and $100 \mu \mathrm{M}$ BrdUTP in place of dTTP, as described in Materials and Methods. DNA was then purified and sedimented to equilibrium in $\mathrm{CsCl}$. Each sample was centrifuged, in a separate tube, at $30,000 \mathrm{rpm}$ in a Beckman model L8-70 ultracentrifuge for $70 \mathrm{~h}$ at $18^{\circ} \mathrm{C}$. Fractions were collected from the bottom of the tube and the radioactivities and the refractive indices of the fractions were determined. (A) Radioactivity profiles following centrifugation of unirradiated pZ189 replicated in the presence of BrdUTP $(\Theta)$ and UV-irradiated $\left(40 \mathrm{~J} / \mathrm{m}^{2}\right) \mathrm{pZ189}$ replicated in the presence of BrdUTP ( $\square$ ). (B) Profile of UVirradiated $\left(40 \mathrm{~J} / \mathrm{m}^{2}\right)$ pZ189 ( $\square$ ) from panel A, shown with an expanded scale for radioactivity. (C) Radioactivity profile of unirradiated pZ189 $(-$, replicated with dTTP instead of BrdUTP. HH, HL, and LL indicate the positions of heavy-heavy, heavy-light, and light-light plasmid DNAs, respectively. The refractive indices of the gradient fractions are shown by solid triangles.

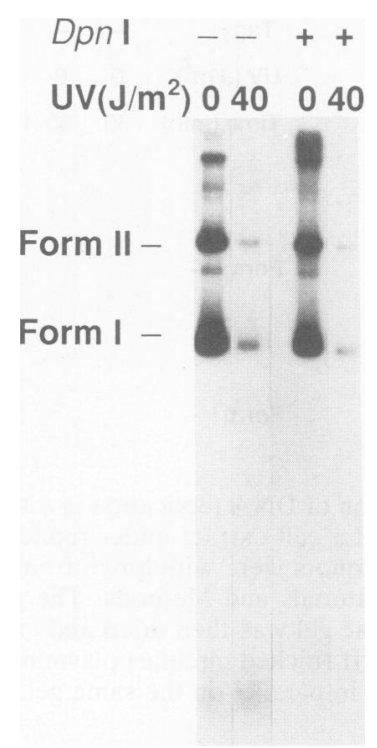

FIG. 6. Treatment of replicated pZ189 with DpnI. Unirradiated and UV-irradiated pZ189 was replicated in HeLa cell extracts in vitro. Following purification in $\mathrm{CsCl}$, the DNA was incubated in the presence or absence of $0.3 \mathrm{U}$ of $D p n \mathrm{I}$, at $37^{\circ} \mathrm{C}$ for $1 \mathrm{~h}$, and then purified by phenol extraction and ethanol precipitation. The products were analyzed by agarose gel electrophoresis in the presence of $5 \mu \mathrm{g}$ of ethidium bromide per $\mathrm{ml}$ followed by autoradiography of the dried gel.

mined by densitometry of an autoradiogram of the gel shown in Fig. 8B). At $50 \mathrm{~J} / \mathrm{m}^{2}$, densitometric analysis of the labeled product DNA demonstrated that the extent of sensitivity to $\mathrm{T} 4$ endonuclease $\mathrm{V}$ increased to almost $60 \%$. This reduced sensitivity, compared with the results obtained with DNA irradiated with $40 \mathrm{~J} / \mathrm{m}^{2}$ replicated in HeLa cell extracts, may be due to increased second-round synthesis, since replication reaction mixtures were incubated for a longer time in experiments with CV-1 extracts.

Treatment of the replicated DNA with $E$. coli photolyase prior to incubation of this DNA with T4 endonuclease V resulted in a loss of sensitivity to nicking by $\mathrm{T} 4$ endonuclease $\mathrm{V}$, indicating that nicking by the endonuclease is primarily due to the presence of pyrimidine cyclobutane dimers in the DNA (Fig. 8C). This rules out the possibility that the observed nicking is due to the presence of abasic sites in the DNA which form cleavage sites for the endonuclease activity of the enzyme. It appears that the photolyase treatment of UV-damaged replicated DNA may have resulted in some conversion of form I to form II DNA. A possible interpretation of this result is that some dimer sites contain nicks in the DNA backbone between the dimerized pyrimidines (a structure proposed by Weinfeld et al. [29]) which are revealed by photolyase treatment.

Pyrimidine cyclobutane dimers remaining in replicated plasmid DNA are not responsible for the observed mutations. We tested the possibility that pyrimidine cyclobutane dimers that remain in the replicated DNA could contribute to the measured mutant frequency in bacteria. Plasmid DNA was treated with photolyase after replication in vitro but before transformation of bacteria. This treatment does not alter the measured mutant frequency in either undamaged or UVdamaged DNA (Table 3). Thus, we conclude that the observed increase in mutant frequency, after transformation of the tester strain with the products of in vitro DNA synthesis, 
TABLE 1. Mutant frequency after transformation of $E$. coli MBM7070 with unreplicated ${ }^{a}$ or with $D p n I$-resistant products of pZ189 DNA replication in vitro

\begin{tabular}{|c|c|c|c|c|c|c|}
\hline \multirow{2}{*}{$\begin{array}{l}\text { Expt. } \\
\text { no. }\end{array}$} & \multirow{2}{*}{$\underset{\left(\mathrm{J} / \mathrm{m}^{2}\right)}{\mathrm{UV}}$} & \multicolumn{2}{|c|}{ Incubation condition } & \multirow{2}{*}{$\begin{array}{l}\text { Total no. } \\
\text { of colonies }\end{array}$} & \multirow{2}{*}{$\begin{array}{l}\text { No. of white } \\
\text { and light blue } \\
\text { colonies }\end{array}$} & \multirow{2}{*}{$\%$ Mutant } \\
\hline & & Extract & $T$ antigen & & & \\
\hline 1 & 0 & - & - & 37,000 & 1 & 0.0027 \\
\hline 1 & 0 & + & - & 13,000 & 0 & $<0.008$ \\
\hline 1 & 0 & + & + & 10,000 & 2 & 0.020 \\
\hline 2 & 0 & + & + & 30,400 & 7 & 0.023 \\
\hline $2^{b}$ & 0 & + & + & 14,200 & 3 & 0.021 \\
\hline 1 & 40 & - & - & 35,600 & 1 & 0.0028 \\
\hline 1 & 40 & + & - & 16,300 & 1 & 0.006 \\
\hline 1 & 40 & + & + & 10,400 & 29 & 0.28 \\
\hline 2 & 40 & + & + & 13,300 & 24 & 0.18 \\
\hline $2^{b}$ & 40 & + & + & 3,100 & 12 & 0.39 \\
\hline
\end{tabular}

a Plasmid, incubated in the absence of extract and/or T antigen, was not treated with DpnI.

$b$ Replicated form I DNA was purified by electroelution from an agarose gel.

does not require the presence of cyclobutane dimers in the DNA transfected into $E$. coli MBM7070.

\section{DISCUSSION}

We have used in vitro DNA replication systems, derived from human HeLa and monkey CV-1 cells, and a shuttle vector plasmid to analyze the effects of UV radiationinduced DNA damage on DNA replication and to determine whether mutation fixation could be shown to occur in vitro. Our results indicate that DNA replication is inhibited in a dose-dependent manner by UV radiation, as reported previously from in vivo studies of SV40 replication $(1,21,25)$ and from studies of plasmid replication of SV40 replication (1, $21,25)$ and from studies of plasmid replication in vitro $(5,6)$. Pyrimidine cyclobutane dimers are the primary UV-induced lesions involved in the inhibition of DNA replication in vitro, since removal of these lesions by photoreactivation of the template before replication reduces the observed inhibition substantially (Fig. 7). We have further demonstrated that the mammalian cell replication complex is capable of complete replication of plasmid DNA containing UV-induced pyrimidine dimers (Fig. 8), as judged by the sensitivity of the completely closed circular progeny molecules to dimerspecific T4 endonuclease $\mathrm{V}$. This replication of plasmids with cyclobutane pyrimidine dimers in the template is accompanied by a 10 - to 20 -fold increase in the mutant frequency in the supF gene of pZ189 (Table 1). Photoreactivation of the DNA before replication reduces the mutant

TABLE 2. Characteristics of 21 mutations recovered following replication of UV-irradiated pZ189 DNA in vitro

\begin{tabular}{llll}
\hline Position $^{a}$ & Sequence $^{b}$ & Change & No. \\
\hline 104,105 & TGGGGT & GG $\rightarrow$ AA & 1 \\
122,123 & AAGGGA & GG $\rightarrow$ AA & 1 \\
127 & AGCAG & C $\rightarrow$ A & 1 \\
129 & CAGAC & G $\rightarrow$ A & 3 \\
138,139 & AATCTG & TC $\rightarrow$ AT & 2 \\
155 & TTCGA & C $\rightarrow$ T & 3 \\
156 & TCGAA & G $\rightarrow$ A & 8 \\
155,156 & TTCGAA & CG $\rightarrow$ AA & 1 \\
163 & TTCGA & C $\rightarrow$ T & 1 \\
\hline
\end{tabular}

a Numbers refer to the base pair position within the supF gene clockwise from the EcoRI site of the plasmid (23).

${ }^{b}$ The letters indicate the base sequences surrounding the sites of mutation (underlined). frequency almost to background, indicating that cyclobutane pyrimidine dimers are the important premutagenic lesions in this system.

The fact that photoreactivation of the UV-irradiated DNA before replication relieves the inhibition of in vitro DNA replication suggests that pyrimidine cyclobutane dimers are primarily responsible for the UV-induced inhibition of DNA replication. This is consistent with interpretations of previous data from UV irradiation of SV40 in monkey cells in vivo $(1,21)$ and from photoreactivation of pZ189 before transfection into monkey cells (17).

Whether recombination plays a role in the process of replication and mutagenesis in this system is not clear, although in vivo studies have indicated that substantial recombination between parental and daughter strands does not occur during replication of UV-damaged SV40 DNA in monkey and human cells in vivo $(14,21)$, making it unlikely that such a process is more active in cell extracts. Furthermore, intermediate-density recombinant molecules were not observed in the density shift experiments reported here.

The mechanism by which replication is inhibited and by which dimer-containing progeny molecules are synthesized is not directly addressed in these experiments. However, the observation of significant levels of DNA replication, under conditions in which $99 \%$ of the input molecules contain pyrimidine cyclobutane dimers, suggests that the presence

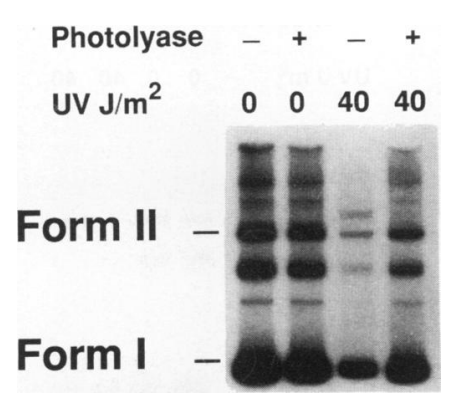

FIG. 7. Restoration of DNA replication by treatment of UVirradiated vector DNA with $E$. coli photolyase. Unirradiated and UV-irradiated $\left(40 \mathrm{~J} / \mathrm{m}^{2}\right)$ vector DNAs were treated with photolyase and 365-nm light as described in Materials and Methods and then replicated in vitro in $\mathrm{HeLa}$ cell extracts for $180 \mathrm{~min}$. DNA not treated with photolyase was replicated in parallel. DNA was purified and electrophoresed on an agarose gel containing $5 \mu \mathrm{g}$ of ethidium bromide per $\mathrm{ml}$, and the dried gel was autoradiographed. 
TABLE 3. Mutant frequency after transformation of $E$. coli with pZ189 DNA treated with $E$. coli photolyase before or after DNA replication

\begin{tabular}{|c|c|c|c|c|c|}
\hline $\begin{array}{l}\text { Expt. } \\
\text { no. }{ }^{a}\end{array}$ & Photolyase treatment & $\begin{array}{l}\text { UV fluence } \\
\qquad\left(\mathrm{J} / \mathrm{m}^{2}\right)\end{array}$ & $\begin{array}{l}\text { Total no. } \\
\text { of colonies }\end{array}$ & $\begin{array}{l}\text { White and light } \\
\text { blue colonies }\end{array}$ & $\%$ Mutant \\
\hline 1 & None $^{b}$ & 0 & 17,500 & 2 & 0.012 \\
\hline 1 & None & 40 & 8,145 & 22 & 0.27 \\
\hline 2 & None & 40 & 5,230 & 21 & 0.32 \\
\hline 1 & Before replication $^{c}$ & 0 & 7,900 & 2 & 0.025 \\
\hline 2 & Before replication & 0 & 31,900 & 6 & 0.019 \\
\hline 1 & Before replication & 40 & 10,500 & 2 & 0.019 \\
\hline 2 & Before replication & 40 & 30,000 & 5 & 0.016 \\
\hline 1 & After replication $^{d}$ & 0 & 16,000 & 2 & 0.013 \\
\hline 1 & After replication & 40 & 1,940 & 5 & 0.26 \\
\hline 2 & After replication & 40 & 1,800 & 8 & 0.38 \\
\hline
\end{tabular}

${ }^{a}$ Experiments 1 and 2 correspond to those shown in Table 1.

$b$ Plasmid was treated as described in footnote $c$ except that photolyase enzyme was omitted.

${ }^{c}$ DNA was treated with $E$. coli photolyase and then purified of this enzyme before use in replication in vitro.

${ }^{d}$ DNA was replicated in vitro and then treated with $E$. coli photolyase. The DNA was purified and used to transform $E$. coli MBM7070.

of these lesions does not completely prevent replication in this system, which is consistent with previous reports of replication of UV-damaged DNA in vitro $(5,6)$. The efficiency with which damage can be tolerated during replication cannot be calculated precisely from these data, since randomly damaged DNA has been used as a template. However, at an average of five dimers per molecule, the residual synthesis of form I molecules was about 15 to $20 \%$ of the control level. This can be compared with about $1 \%$ residual undamaged molecules in the input DNA and about $14 \%$ of molecules with damage on only one of the two strands. Thus, the observed level of replication could reflect replication of only those molecules with an undamaged leading (or lagging) strand or reduced replication of molecules with damage on either strand. The results shown in Fig. 8A indicate that between 80 and $90 \%$ of the labeled form I DNA, resulting from replication of UV-irradiated plasmid, is sensitive to nicking by $\mathrm{T} 4$ endonuclease $\mathrm{V}$. This value is higher than would be expected if replication is restricted to molecules with damage in only one strand. In that case, one round of replication would result in progeny molecules of which one would contain at least one dimer in the parental strand and one would have an undamaged parental strand and therefore be resistant to nicking by $\mathrm{T} 4$ endonuclease $\mathrm{V}$; in this case, a maximum of $50 \%$ of the replicated molecules would be sensitive to $\mathrm{T} 4$ endonuclease $\mathrm{V}$ nicking. Our data do not rule out the possibility that accommodation of some dimers during replication is facilitated by modification of those pyrimidine dimer sites by, for example, disruption of the phosphodiester bond between the two pyrimidines of the dimer (29). It has been suggested, from studies of replication of SV40 in vivo, that a single dimer on the leading strand for replication can block both DNA synthesis and replication fork progression while a dimer on the lagging strand may lead to a single-stranded gap at the site of the dimer but not block fork progression $(1,21)$. The filling of these gaps may be an important step in both replication and mutagenesis of damaged templates (30). The present data support the idea that dimers can be accommodated by the replication machinery at low efficiency but do not address the importance of the position of the dimer on the leading or lagging strand. To investigate this question, plasmids containing site- and strand-specific lesions would be required.

The observation that mutants arise during replication of UV-damaged plasmid in vitro is consistent with the fact that some dimer-containing molecules become completely repli-

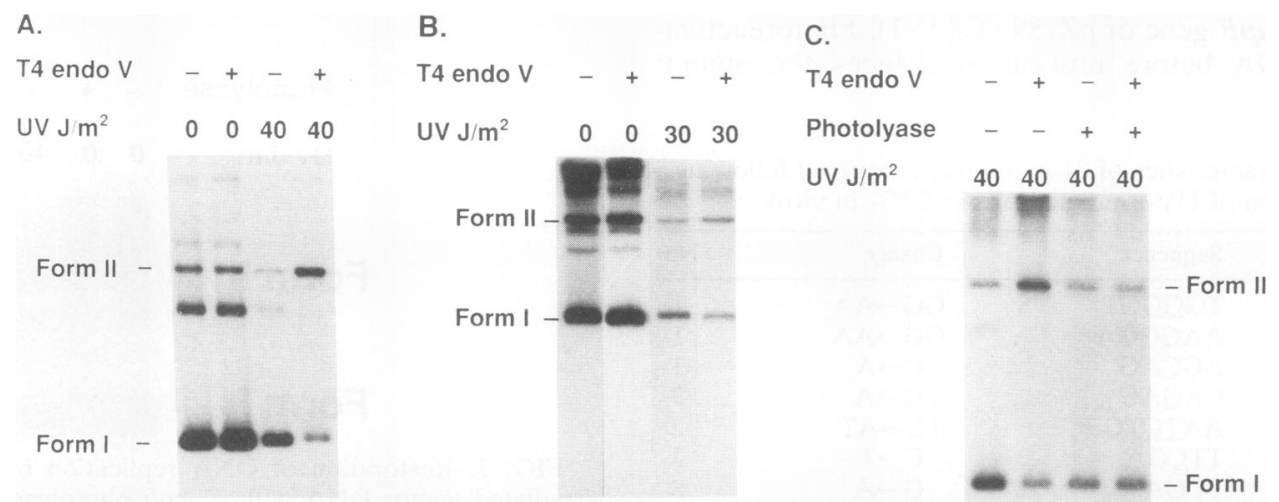

FIG. 8. Treatment of replicated vector DNA with $\mathrm{T} 4$ endonuclease $\mathrm{V}$ and $E$. coli photolyase. Unirradiated and UV-irradiated vector DNAs were replicated in HeLa cell extracts for $180 \mathrm{~min}$ or in CV-1 cell extracts for $420 \mathrm{~min}$. DNA was then purified and treated with T4 endonuclease $\mathrm{V}$, photolyase, or photolyase followed by T4 endonuclease $\mathrm{V}$. The DNA was then repurified and electrophoresed on an agarose gel with ethidium bromide. (A) Replication in HeLa extract and treatment with or without T4 endonuclease V. (B) Replication in CV-1 extract and treatment with or without T4 endonuclease V. (C) Replication in HeLa extract and treatment with $E$. coli photolyase followed by treatment with or without T4 endonuclease V. 
cated. Photoreactivation of damaged DNA before replication results in a reduction of the mutant frequency to the levels seen with undamaged DNA (Table 1), suggesting that cyclobutane pyrimidine dimers are the major premutagenic lesions in vitro. This result is consistent with data from in vivo experiments in which pZ189 DNA was photoreactivated before transfection into monkey cells (17). Our data do not address the mutagenic potential of (6-4)-photoproducts (15) during DNA replication in vitro. Our preliminary data showing a predominance of $\mathrm{G}: \mathrm{C} \rightarrow \mathrm{A}: \mathrm{T}$ transitions among mutations arising in vitro are similar to in vivo results, which suggests that the mechanisms of mutation fixation that occur in the in vitro DNA replication system may be similar to mechanisms of mutagenesis in vivo. Since these mutations occur predominantly at dipyrimidine sites in the template, these data are consistent with misincorporation of bases opposite pyrimidine cyclobutane dimers resulting from replication in vitro.

The identities of the components of the replication apparatus which are inhibited by UV radiation are not defined. A previous analysis indicated that the helicase activity of SV40 large $T$ antigen in vitro was not inhibited substantially at a dimer load of three to four dimers to the DNA substrate (6). UV photoproducts have been shown to inhibit DNA synthesis by purified polymerase $\alpha$ in vitro (16). It has been proposed that two polymerases are active during in vitro replication in extracts of primate cells such as those used here. Polymerase $\alpha$ is the lagging strand polymerase, and polymerase $\delta$ is the leading strand polymerase $(11,27)$. The ability of polymerase $\delta$ to copy UV-irradiated templates has not been well investigated until this point. The asymmetric nature of the replication complex could play a role in determining whether a dimer on the leading or lagging strand results in blockage of the replication fork and whether correct or mutagenic bypass of the lesion occurs. If, as suggested by in vivo studies (30), single-stranded gaps are generated opposite of sites of damage during replication of damaged templates, the DNA polymerase involved in gap filling may be responsible for base misincorporation and mutagenesis. In $E$. coli, fixation of UV-induced lesions as mutations requires the induction of a number of proteins of the SOS response, in addition to the normal replication apparatus (28). These proteins include RecA and the umuDC gene products (28). Whether analogous proteins are involved in replication and mutagenesis of UV-damaged DNA in mammalian cells could be addressed by using a system such as that described here. In any case, it appears that the proteins present in the extract are capable of fixation of mutations. The ability of extracts of primate cells to carry out replication of UV-damaged templates and mutation fixation in vitro should facilitate further analysis of the biochemistry of these processes.

\section{ACKNOWLEDGMENTS}

We gratefully acknowledge the technical assistance of Kathryn Mielke. We thank Aziz Sancar for the generous gift of $E$. coli photolyase. We appreciate the helpful advice of Joel Jessee in improving transformation efficiencies. We appreciate the many helpful discussions with Saleh El Saleh. We thank Alvaro Puga and Daniel W. Nebert for critical reading of the manuscript.

This work was supported in part by grant ES05400 to K.D. from the National Institute of Environmental Health Sciences. This work was also supported in part by NIH grant 1 P30 ES06096.

\section{REFERENCES}

1. Berger, C. A., and H. J. Edenberg. 1986. Pyrimidine dimers block simian virus 40 replication forks. Mol. Cell. Biol. 6:34433450.

2. Brash, D. E., S. Seetharam, K. H. Kraemer, M. M. Seidman, and A. Bredberg. 1987. Photoproduct frequency is not the major determinant of UV base substitution hot spots or cold spots in human cells. Proc. Natl. Acad. Sci. USA 84:3782-3786.

3. Bredberg, A., K. H. Kraemer, and M. M. Seidman. 1986. Restricted ultraviolet mutational spectrum in a shuttle vector propagated in xeroderma pigmentosum cells. Proc. Natl. Acad. Sci. USA 83:8273-8277.

4. Carty, M. P., Y. Ishimi, A. S. Levine, and K. Dixon. 1990. DNA polymerase alpha from HeLa cells synthesizes DNA with high fidelity in a reconstituted replication system. Mutat. Res. 232: 141-153.

5. Dixon, K., J. Hauser, E. Roilides, and A. S. Levine. 1988. Use of an SV40-based shuttle vector in vivo and in vitro for studies on the mechanisms of mammalian mutagenesis. UCLA Symp. Mol. Cell. Biol. 83:491-498.

6. Gough, G., and R. D. Wood. 1989. Inhibition of in vitro SV40 DNA replication by ultraviolet light. Mutat. Res. 227:193-197.

7. Hauser, J., A. S. Levine, and K. Dixon. 1987. Unique pattern of point mutation arising after gene transfer into mammalian cells. EMBO J. 6:63-67.

8. Hauser, J., A. S. Levine, and K. Dixon. 1988. Fidelity of DNA replication in a mammalian in vitro replication system. Mol. Cell. Biol. 8:3267-3271.

9. Hauser, J., M. M. Seidman, K. Sidur, and K. Dixon. 1986. Sequence specificity of point mutations induced during passage of a UV-irradiated shuttle vector plasmid in monkey cells. Mol. Cell. Biol. 6:277-285.

10. Kaufmann, W. K., and J. E. Cleaver. 1981. Mechanisms of inhibition of DNA replication by ultraviolet radiation in normal human and xeroderma pigmentosum fibroblasts. J. Mol. Biol. 149:171-187.

11. Lee, S.-H., T. Eki, and J. Hurwitz. 1989. Synthesis of DNA containing the simian virus 40 origin of replication by the combined action of DNA polymerases alpha and delta. Proc. Natl. Acad. Sci. USA 86:7361-7365.

12. Lehmann, A. R. 1972. Postreplication repair of DNA in ultraviolet-irradiated mammalian cells. J. Mol. Biol. 66:319-337.

13. Li, J. J., and T. J. Kelly. 1984. Simian virus 40 DNA replication in vitro. Proc. Natl. Acad. Sci. USA 81:6973-6977.

14. Mezzina, M., C. F. M. Menck, P. Courtin, and A. Sarasin. 1988. Replication of simian virus 40 DNA after UV irradiation: evidence of growing fork blockage and single-stranded gaps in daughter strands. J. Virol. 62:4249-4258.

15. Mitchell, D. L., and R. S. Nairn. 1989. The biology of the (6-4) photoproducts. Photochem. Photobiol. 49:805-819.

16. Moore, P. D., K. K. Bose, S. D. Rabkin, and B. S. Strauss. 1981. Sites of termination of in vitro DNA synthesis on ultravioletand $N$-acetylaminofluorene-treated phi-X174 templates by prokaryotic and eukaryotic DNA polymerases. Proc. Natl. Acad. Sci. USA 78:110-114.

17. Protić-Sabljić, M., N. Tuteja, P. J. Munson, J. Hauser, K. H. Kraemer, and K. Dixon. 1986. UV light-induced pyrimidine dimers are mutagenic in mammalian cells. Mol. Cell. Biol. 6:3349-3356.

18. Rabkin, S. D., P. D. Moore, and B. S. Strauss. 1983. In vitro bypass of UV-induced lesions by Escherichia coli DNA polymerase I: specificity of nucleotide incorporation. Proc. Natl. Acad. Sci. USA 80:1541-1545.

19. Roberts, J. D., and T. A. Kunkel. 1988. Fidelity of a human cell replication complex. Proc. Natl. Acad. Sci. USA 85:7046-7068.

20. Sancar, A., F. W. Smith, and G. B. Sancar. 1984. Purification of Escherichia coli DNA photolyase. J. Biol. Chem. 259:60286032.

21. Sarasin, A. R., and P. C. Hanawalt. 1980. Replication of ultraviolet-irradiated simian virus $\mathbf{4 0}$ in monkey kidney cells. J. Mol. Biol. 138:299-319.

22. Seawell, P. C., E. C. Friedberg, A. K. Ganesan, and P. C. Hanawalt. 1981. Purification of endonuclease $V$ of bacterio- 
phage T4, p. 229-236. In E. C. Friedberg and P. C. Hanawalt (ed.), DNA repair: a laboratory manual of research procedures, vol. 1. Marcel Dekker, Inc., New York.

23. Seidman, M. M., K. Dixon, A. Razzaque, R. Zagursky, and M. L. Berman. 1985. A shuttle vector plasmid for studying carcinogen-induced point mutations in mammalian cells. Gene 38:233-237.

24. Silverberg, E., and J. A. Lubera. 1989. Cancer statistics 1989. CA Cancer J. Clin. 39:3-39.

25. Stacks, P. C., J. H. White, and K. Dixon. 1983. Accommodation of pyrimidine dimers during replication of UV-damaged simian virus 40 DNA. Mol. Cell. Biol. 3:1403-1411.

26. Stillman, B. W., and Y. Gluzman. 1985. Replication and supercoiling of simian virus 40 DNA in cell extracts from human cells. Mol. Cell. Biol. 5:2051-2060.

27. Tsurimoto, T., T. Melendy, and B. Stillman. 1990. Sequential initiation of leading and lagging strand synthesis by two different polymerase complexes at the SV40 replication origin. Nature (London) 346:534-539.

28. Walker, G. C. 1984 . Mutagenesis and inducible responses to deoxyribonucleic acid damage in Escherichia coli. Microbiol. Rev. 48:60-93.

29. Weinfeld, M., N. E. Gentner, L. D. Johnson, and M. C. Paterson. 1986. Photoreversal-dependent release of thymidine and thymidine monophosphate from pyrimidine dimer-containing DNA excision fragments isolated from ultraviolet-damaged human fibroblasts. Biochemistry 25:2656-2664.

30. White, J. H., and K. Dixon. 1984. Gap filling and not replication fork progression is the rate-limiting step in the replication of UV-damaged simian virus 40 DNA. Mol. Cell. Biol. 4:12861292. 